\title{
Lean Management in Obstetrics and Gynecology: Application in the Ambulatory Clinic Pre- and Post-Kaizen
}

\author{
Michele Follen ${ }^{1,2}$, Leo Fradkin ${ }^{3}$, Joseph Crane ${ }^{2,4}$, Chuck Noon ${ }^{2}$ \\ ${ }^{1}$ Kings County Hospital, Clarkson, Brooklyn, NY, USA \\ ${ }^{2}$ University of Tennessee, Haslam College of Business, Knoxville, TN, USA \\ ${ }^{3}$ Brookdale Hospital and Medcial Center, One Brookdale Plaza, Brooklyn, NY, USA \\ ${ }^{4}$ Teamhealth INC, Knoxville, TN, USA \\ Email: *michelefollen@gmail.com
}

How to cite this paper: Follen, M., Fradkin, L., Crane, J. and Noon, C. (2018) Lean Management in Obstetrics and Gynecology: Application in the Ambulatory Clinic Pre- and Post-Kaizen. Open Journal of Obstetrics and Gynecology, 8, 1604-1630. https://doi.org/10.4236/ojog.2018.814161

Received: November 14, 2018 Accepted: December 26, 2018

Published: December 29, 2018

Copyright $\odot 2018$ by authors and Scientific Research Publishing Inc. This work is licensed under the Creative Commons Attribution International License (CC BY 4.0).

http://creativecommons.org/licenses/by/4.0/

\begin{abstract}
OBJECTIVE: The ambulatory clinic was an important departmental problem. Providers hated working there and patients complained about the wait times there. It seemed there were equal numbers of patients and provider complaints. In the spirit of solving the problem, data was gathered, a LEAN intervention was planned, and data was collected. METHODS: We defined the service families in the clinic as registration, vital signs, provider or ultrasound visit, nursing visit, and registration for the return visit. We walked the Gemba engaging all the staff in the process. Many observations pointed to long waits between and among the five stations. In order to study the current state, time data was collected by attaching a sheet of paper to a folder that the patient would carry themselves to all the clinical steps. On the sheet of paper each station logged the time that patient appeared and the time the patient left their sight. Data was gathered each day and every day from October 2016 to the summer of 2017. The data was analyzed. Leadership met and identified value and waste in the process. A Kaizen event was scheduled after the first set of measurements engaging all the staff. After the data was thoroughly analyzed and digested, brainstorming occurred. Together we determined our future state. We created a vision and strategic goals to reach our future state. RESULTS: The data pre-Kaizen event showed that the process of arrival to leaving took 124 minutes. We discovered that not every patient passed through each station. We learned the patients were on time or early for their visit most of the time. The providers were late most of the time by $1-1.5$ hours. We learned how long each station took from the patient's point of view. There were no statistically significant differences between ultrasound
\end{abstract}


and provider visits; there were no statistically significant differences between midwife and physician visits. Each day of the week was similar. The arrival rate was higher in the morning because of the template. After the event, the total time in clinic did not change however the variability in time between and among each station decreased in variance. We informed the staff of these findings so that they could take responsibility for their part in the process. The atmosphere in clinic changed dramatically and the complaints from both providers and patients stopped. CONCLUSION: LEAN management was used to improve the clinic. It yielded important results, got the staff engaged in the process, and provided a way for the patients to see the efforts made by staff to improve.

\section{Keywords}

Lean Management Healthcare, LEAN and Obstetrics and Gynecology, Lean and Ambulatory Care, Lean and Women's Health

\section{Introduction}

Lean Management is a philosophy of management coined by Womack et al. as "LEAN management" used to describe the Toyota Production System. Toyota was wildly successful and led the world in car production and sales overtaking Ford, General Motors, and Chrysler in the 1990's. This fact led many Americans to flock to the Toyota factory to learn how TPS worked. TPS was a combination of philosophies involving lessons from post-war Japan, the teachings of W. Edwards Deming, use of statistical process tools developed by Walter A. Shewhart, the Toyoda family itself, Taiichi Ohno their plant manager, and Japanese culture. James P. Womack at the Massachusetts Institute of Technology and Jeffrey K. Liker at the University of Michigan 1992, published many comprehensive texts and designed many training programs [1] [2] [3] [4] [5]. Katz and Greene were the first to bring Deming to healthcare [6] [7].

The Toyoda family built its wealth in textile production (the family name is Toyoda and the company name became Toyota). The founding principles for TPS were developed in their textile factory using looms designed by Sakichi Toyoda. (Ohno) Sakichi remained focused on quality and his customer. He designed his loom machine to stop when the thread broke; allowing a perfect product to be generated time after time [8]-[13]. Toyoda spend hours in the factory and on the floor of the factory observing the flow of work [14]-[21]. He is credited with the five why's (asking why five times before accepting the answer) and the five S's (Seiri (Sort), Seiton (Straighten, Set), Seiso (Shine, Sweep), Seiketsu (Standardize), and Shitsuke (Sustain)). His son Kichiro Toyoda launched the company in 1933. The Toyota floor manager for the textile company was Taiichi Ohno, a philosophical guru, in his own right. These three men: Sakichi Toyoda, Kichrio Toyoda, and Taiichi Ohno, transformed the world of manage- 
ment in a few decades [22] [23] [24] [25] [26].

Post war Japan had little industrial strength except in textiles where they competed favorably with the English who were world leaders at the time. After selling the patents for their loom to the English, they began their automobile manufacturing group. Sakichi Toyoda was inspired by W. Edwards Deming and the American auto industry. Kichiro visited the Ford manufacturing plant and American grocery stores many times. Deming held many seminars in post war Japan with engineers and other leaders of industry. Deming is credited with the Plan-Do-Check-Act cycle which used in many aspects of management. Deming created principles of his philosophy which are featured in Table 1 . The essential message revolved around quality and pursuing long term objectives, eschewing short term measures of economic gain. He also emphasized empowerment of workers to keep them engaged.

Deming had a capable statistical partner in Shewhart who focused on statistical process control. His work objectified the processes and offered a way to measure pre- and post-change events [1] [2] [3] [4].

Womack, Jones, and Roos published the text "The Machine that Changed the World" in 2007. Liker and Hoseus published "Toyota Culture" in 2008. Both Womack and Liker began training institutes to teach LEAN to American industry and management. After Womack and Liker published several texts, the TPS began diffusing first through the auto industry, then to management systems, and finally to the service industry. Liker's Principles of TPS emphasize many of Deming's, Sakichi Toyoda, and Taichii Ohno's thoughts. Liker's table is seen as Table 2. As Deming emphasized long term thinking; Sakichi Toyoda emphasized making the customer's view the standard; and Kachiri Toyoda and Ohno emphasized long term problem solving and worker empowerment. The Japanese culture contributed the continuous improvement model which is essential to TPS [22] [23] [25].

Table 1. Deming's principles.

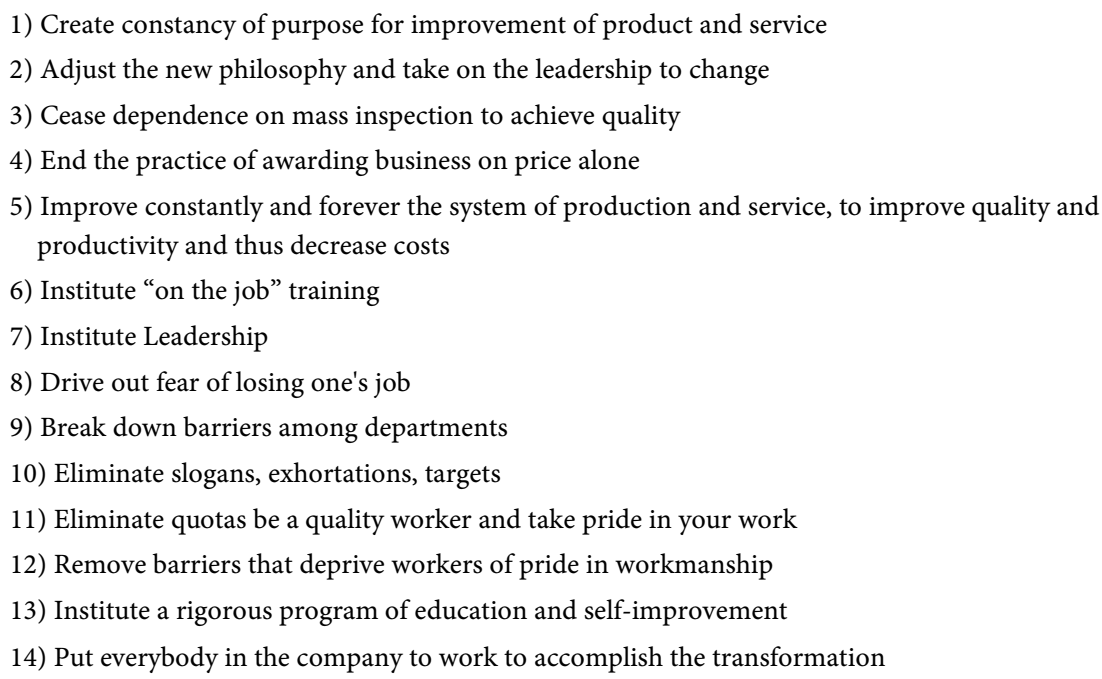


Both Womack and Liker worked hard to increase diffusion of the concepts. See Figure 1 Womack's Lean Summary Circle. When lean management diffused to the service industry, it began to be used in healthcare in the U.S. and England [6] [7] [27]-[48]. A thorough review of that diffusion is found in Follen M. et al. Lean Management in Obstetrics and Gynecology: History and Background (in press). The field of obstetrics and gynecology offers many sites for Lean Management: the ambulatory clinic, the delivery room (an operating room, emergency

Table 2. Liker's principles of the Toyota production system.

Long Term Philosophy

Principle 1 Base your management decisions on a long-term philosophy, even at the expense of short-term goals

\section{The Right Process Will Produce the Right results}

Principle 2 Create continuous process flow to bring problems to the surface

Principle 3 Use "pull" systems to avoid overproduction

Principle 4 Level out the workload (Heijunka)

Principle 5 Build a culture of stopping to fix problems to get quality right the first time

Principle 6 Standardized Tasks are the foundation of continuous improvement and employee empowerment

Principle 7 Use visual control so no problems are hidden

Principle 8 Use only reliable, thoroughly tested technology that serves your people and processes

\section{Add Value to the Organization by Developing People and Partners}

Principle 9 Grow leaders who thoroughly understand he work, live the philosophy, and teach it to others

Principle 10 Develop exceptional people and teams who follow your company's philosophy

Principle 11 Respect your extended network of partners and suppliers by challenging them and helping them improve

\section{Continuously Solving Root Problems Drives Organizational Learning}

Principle 12 Go and See for yourself to thoroughly understand the situation (Genchi Genbutsu)

Principle 13 Make Decisions slowly by consensus thoroughly reviewing all options; implement decisions rapidly

Principle 14 Become a learning organization through relentless reflection and continuous improvement (kaizen)

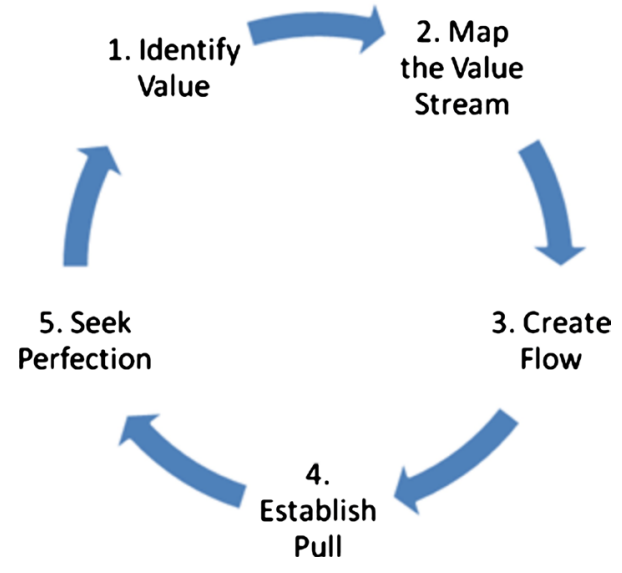

Figure 1. Womack's LEAN summary circle. 
room and intensive care unit), and the gynecology operating room.

The clinic was considered the most unpleasant place for patients and the worst duty for doctors and midwives. The patients would often scream about the wait and security guards would rush down to protect employees from threatened harm. It was hard to tell how long people were waiting because there were no visual clues that told neither clinic employees nor patients how long had anyone been waiting and who was in the queue. There was just a waiting room of angry patients. The registration clerks were surly; the medical assistants were crowded into a little room in the middle of the back of the clinic and could only see one patient at a time; each provider had only one room; and the nurse visit was the last stop on the way. The line for the nurses was long. The time stamps on the charts in EPIC's electronic medical records, showed wait of 2 - 4 hours in our clinic. The patient complaints seemed justified. The clinic system was its own division of the hospital and it seemed impossible to fix it. We campaigned hard with the Executive Suite to have authority over our department's space, hiring, and destiny.

We found that we did have positions assigned to our department for registration clerks, medical assistants, providers, discharge clerks, but not for nurses. We were assigned two nurses but by separating from the structure, we were given only one nurse. The staff was excited to function as a unit and have more control over our future.

\section{Methods}

We approached the clinic with a LEAN framework. 1) Identifying Value: We identified value from the patient's point of view; noting that waiting was a waste. 2) Map the Value Stream: We conducted Value Stream Mapping (VSM) which involves six elements: defining service families, walking the Gemba or clinic to observe the flow of patients, completing a current state flow map, identifying value added and non-value added activities in the flow, creating a future state flow map, and planning our improvement strategy. The strategy included careful scrutiny of the data collected to answer many questions about our operations and their variability. 3) Create Flow: We examined our Value Stream Map to see where we could create flow. 4) Establish Pull: We examined the flow to see where we could create pull. 5) Seek Perfection (Continuous improvement) we tried to create perfection to the best of our ability.

In preparation the event, we designed a time flow sheet that would accompany each patient's folder and we asked each employee to write down the time they encountered the patient and when they finished their task. We then planned a KAIZEN event to present the data, to obtain staff engagement, and to set the stage for improvement. We measured again after the event to see what factors changed.

What we learned from our reading was that the Toyodas and Ohno were always curious and observant. They asked a series of questions as they solved each problem. In that spirit, we show the results as answers to a number of questions. 


\section{Results}

\subsection{Identify Value: Learning to See}

We thought carefully about how to see the experience from the Patient's Point of View. All members of the team took time to observe the clinic processes after we gathered the data.

\subsection{Value Stream Mapping}

\section{STEP ONE: DEFINE SERVICE FAMILIES}

In the clinic, there are many different types of visits. They can broadly be divided among provider visits and fetal testing or ultrasound visits. Fetal testing includes both ultrasound and biophysical profiles (which incorporate ultrasound). There are several providers including doctors and midwives. Services include high risk obstetrics, low risk obstetrics, routine gynecology, emergent gynecology, uro-gynecology, gynecologic oncology, family planning, colposcopy, and cancer screening. We also carried out research trials in the outpatient setting. Figure 2 shows the initial Value Stream Map.

\section{STEP TWO: GATHER YOUR TEAM AND WALK THE PROCESS}

As the leader of the team, I chose six team members: the departmental administrator, a nurse practitioner, a research assistant, an executive assistant who aspired to be a clinic director, a data analyst, and our departmental secretary. All the clinic staff was aware that making the clinic more customer centric was critical. The largest number of complaints was about time so we decided to study the time and if it was indeed long, to try to decrease it.

STEP THREE: COMPLETE CURRENT STATE MAP

We mapped out a Basic Process Map shown in the figure that follows. Patient entered the clinic and went to reception where they registered. They went to the waiting room. The medical assistants called them to another room where vital

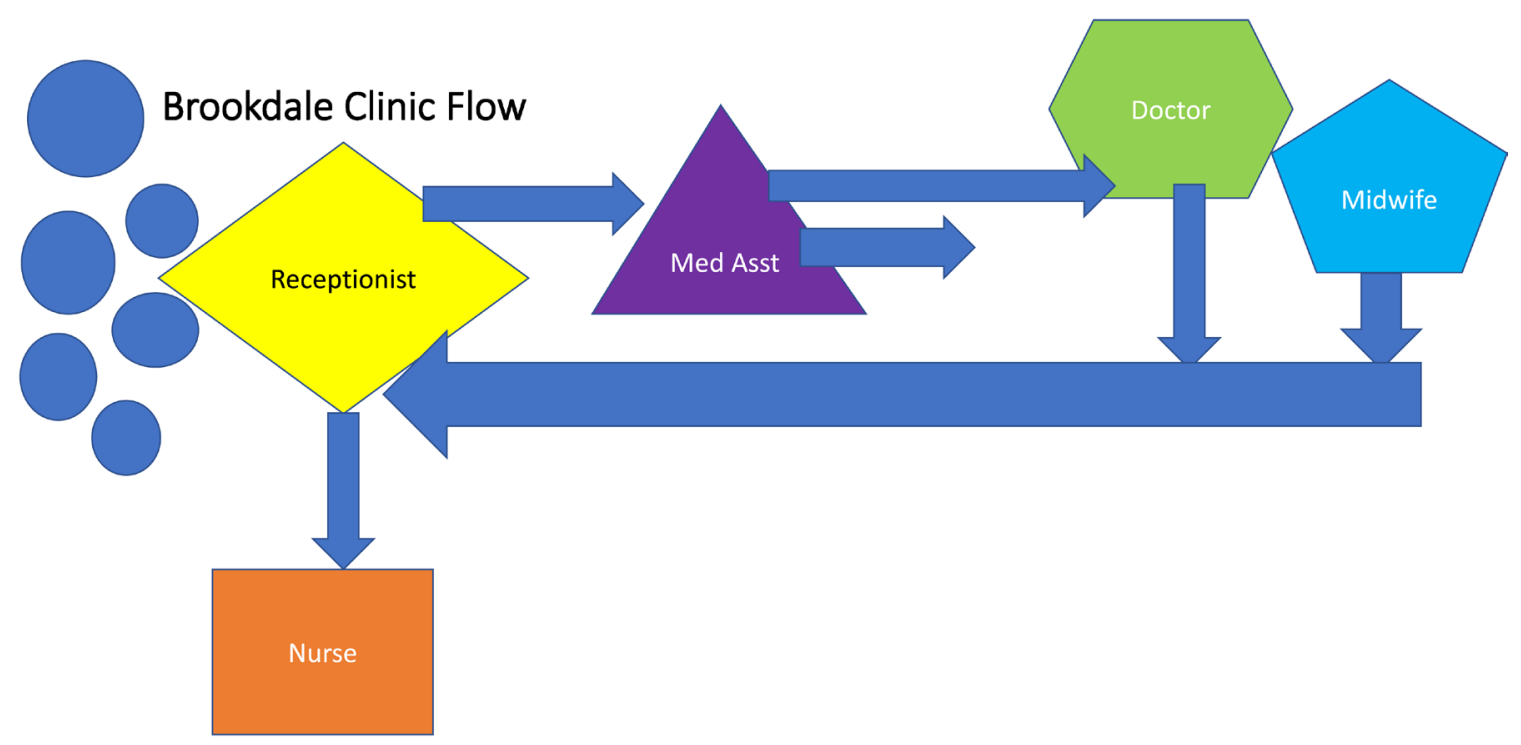

Figure 2. Basic process map. 
signs were taken. They returned to the waiting room. The provided identified the next patient and came to the waiting room to call their name. The provider saw the patient and sent the patient to the registration are to checkout. The provider also indicated whether a visit with the nurse was necessary. The patient either saw or didn't see the nurse and then left.

STEP FOUR: IDENTIFY VALUE AND WASTE AND WHERE LEAN TOOLS ARE NEEDED

We believed that all four or five steps were necessary and added value and that any wait time was waste. We constructed a more detailed flow map and we focused on a data collection tool.

WHAT DID THE DATA LOOK LIKE?

Table 3 shows a sample the data as entered on the collection form. All the data was placed in Excel spreadsheets and all calculations were made in minutes. QueueCalc (an Excel function) provides a poison model to analyze queuing. It

Table 3. Data collection instrument.

\begin{tabular}{|c|c|c|}
\hline $10 / 24 / 16$ & 1 & 2 \\
\hline \multicolumn{3}{|l|}{ Arrival } \\
\hline Appt Time & 11:15 AM & 8:30 AM \\
\hline Arrival Time & 8:06 AM & $8: 16$ AM \\
\hline Early by How Many Minutes & 187.00 & 14.00 \\
\hline \multicolumn{3}{|l|}{ On Time } \\
\hline \multicolumn{3}{|l|}{ Late by How Many Minutes } \\
\hline \multicolumn{3}{|l|}{ Registration } \\
\hline Start & $8: 20 \mathrm{AM}$ & 8:22 AM \\
\hline Stop & 8:22 AM & $8: 23 \mathrm{AM}$ \\
\hline Total Time & 2.00 & 1.00 \\
\hline \multicolumn{3}{|l|}{$\underline{\text { Vitals }}$} \\
\hline Start & 8:23 AM & 8:27 AM \\
\hline Stop & 8:27 AM & $8: 33 \mathrm{AM}$ \\
\hline Total Time & 4.00 & 6.00 \\
\hline \multicolumn{3}{|l|}{ Provider } \\
\hline \multicolumn{3}{|l|}{ Midwife/Doc? } \\
\hline Start & 8:40 AM & 9:05 AM \\
\hline Stop & 9:00 AM & 9:25 AM \\
\hline Total Time & 20.00 & 20.00 \\
\hline \multicolumn{3}{|l|}{ Check-out } \\
\hline Start & 9:03 AM & 9:33 AM \\
\hline Stop & 9:04 AM & 9:34 AM \\
\hline Total Time & 1.00 & 1.00 \\
\hline \multicolumn{3}{|l|}{ Nursing } \\
\hline Start & 9:05 AM & 9:36 AM \\
\hline Stop & 9:18 AM & 9:49 AM \\
\hline Total Time & 13.00 & 13.00 \\
\hline
\end{tabular}


can be used both to calculate how many patients are arriving at each station and it can be used retrospectively using the length of the queue to analyzed how much of the relevant task is being accomplished by employees engaged in the flow.

\section{STEP FIVE: COMPLETE FUTURE STATE MAP}

We decided that our future state would have the same stations but that we would cut the total time in clinic by one third, try to see $33 \%$ more patients, and make a huddle board with our data and efforts so that both staff and patients could be engaged.

STEP SIX: CREATE YOUR OWN VISION, STRATEGY AND PLAN

Our Vision was to make the clinic more efficient. Our strategy was to use LEAN tools. We prepared for 4 - 8 weeks for a KAIZEN event by collecting data. We decided to launch the KAIZEN event, perform our interventions, and then re-measure and re-evaluate.

\subsection{How Could We Study This?}

We collected data for about two months and entered the data into the computer. Some employees used military time and others used non-military time. The data were corrected to one system and the time spent in each station was calculated as was the time spent between stations.

\subsection{What Happens in Clinic?}

The first analysis showed that unlike what we thought was happening; it was not. We thought everyone went through each step in the flow of the clinic. We learned that whether patients were there to see the providers or for fetal testing, they didn't always get the vital signs taken (17\% did not) and they didn't always checkout (11\% did not). Vital signs are critical parts of the exam, especially in our high-risk obstetrical population. Not going through the checkout process meant that they were not always getting their meaning use documents nor were they confirming a follow-up appointment. We also learned that only $40 \%$ of patients saw the nurse. Table 4 shows these results.

\subsection{How Long Does Everything Take?}

We wondered why patients were in clinic for such a long time. What was the

Table 4. Average flow through each station collected from the October/November Data Set.

\begin{tabular}{lc}
\hline DATES & OCT/NOV 2016 \\
\hline Average number of Patients who go through Registration & $98 \%$ \\
Average number of Patients who get Vital Signs & $83 \%$ \\
Average number of Provider Visits/Total visits & $44 \%$ \\
Average number of USG/BPP visits & $56 \%$ \\
Average number of Patients who go through Checkout & $89 \%$ \\
Average number of Patients who see Nursing & $40 \%$ \\
\hline
\end{tabular}


average time did they spend in each activity? We used Excel to calculate the mean, median, standard deviation, and range of each measurement in minutes. Table 5 shows the average time and the range. The medians did not differ significantly from the means (data not shown).

\subsection{Were the Patients Arriving on Time?}

Almost everyone in the clinic accused the patients of arriving late. From the clerks to the providers and even nursed believed that the patients were the problem. When we studied the on time, early arrival and late arrival, we were surprised. Roughly $5 \%$ of patient arrived on time; fully $55 \%$ arrived early, and only $40 \%$ arrived late. Those that arrived early, arrived an average of 36 minutes early and those that arrived late arrived an average of 34 minutes late. Previous administrations thought they needed to "retrain" the patients; however, given that we are in Brooklyn, nearly all the patients arrive on public transportation. It now seemed that the patients were more often early or on time and even when they were late, it was only by 30 minutes. Clearly the patients were doing a good job and the clinical staff were wrong.

\subsection{Were Provider Visits Longer or Shorter Than Ultrasound Visits? Was One a Problem and Not the Other?}

We were stupefied to find that although the patients were indeed in clinic for 2 hours and also that only 34 minutes of their 124 minutes were value added time. What could account for the long waits? Could it be that the long waits were for fetal testing and not for midwives and doctors? Figure 3 shows the mean time for both ultrasound and provider visits. No statistically significant difference is noted.

We examined the total time in clinic for providers versus fetal testing and it was the same. The type of visit was not the problem. In these figures we compare total time for midwife versus total time for ultrasound and fetal testing and total time for physician versus ultrasound and fetal testing. Figure 4 shows that the total time in clinic was the same for both activities.

Table 5. Average time spent in each station in clinic and the range.

\begin{tabular}{lc}
\hline DATES & OCT/NOV 2016 \\
\hline Average Number Patients seen (average range) & $35(29-44)$ \\
Average Patients Who Left without being seen (average range) & $1(0-3)$ \\
Average Time In Registration (average range of minutes) & $2.6 \mathrm{~min}(1.3-4.2)$ \\
Average Time Vital Signs (average range of minutes) & $4.5 \mathrm{~min}(2.97-5.79)$ \\
Average Time with Providers (average range of minutes) & $16 \mathrm{~min}(10-20)$ \\
Average Time for Check out (average range of minutes) & $2.3 \mathrm{~min}(1.5-3.2)$ \\
Average Time in Nursing (average range of minutes) & $8.2 \mathrm{~min}(6.7-9.8)$ \\
Average Total Time from Triage to Providers or Ultrasound \\
(average range of minutes)
\end{tabular}




\subsection{Did Doctors and Midwives Differ in Triage or Total Time?}

Could it be that there was a difference between doctors and midwives? We examined the differences between doctors and midwives. We theorized that midwives would spend more time with the patients than physicians. Figure 5 shows

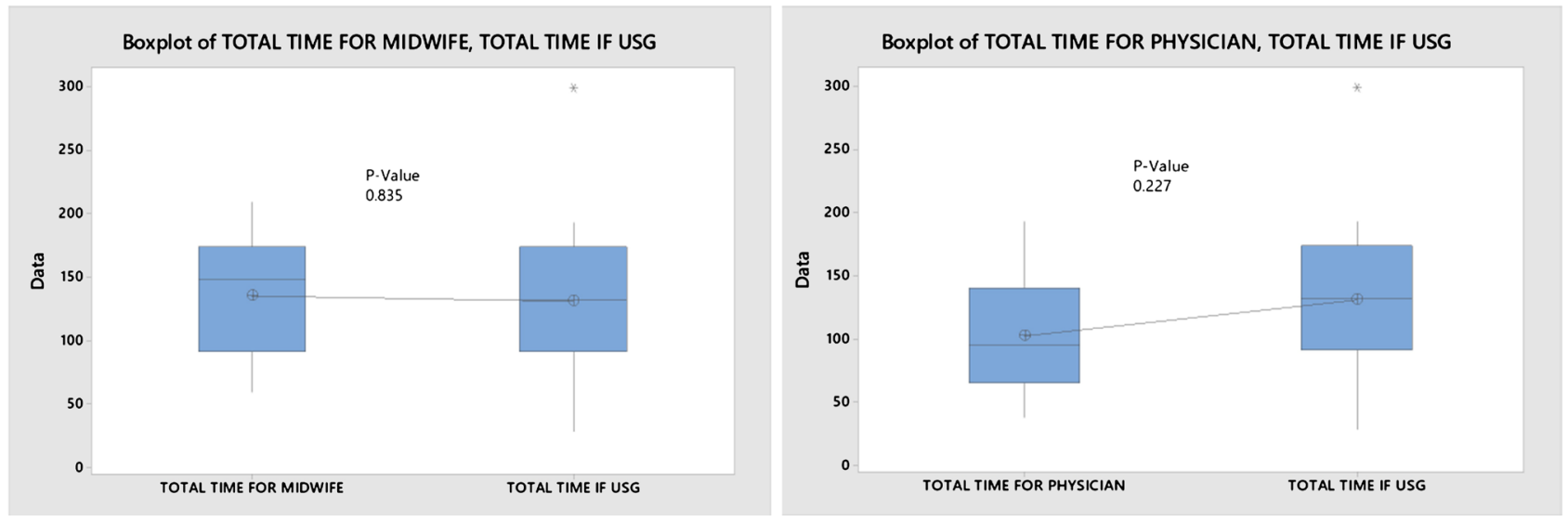

Figure 3. Boxplots and $\mathrm{P}$ values that compare midwife versus ultrasound and fetal testing and physician versus ultrasound and fetal testing.
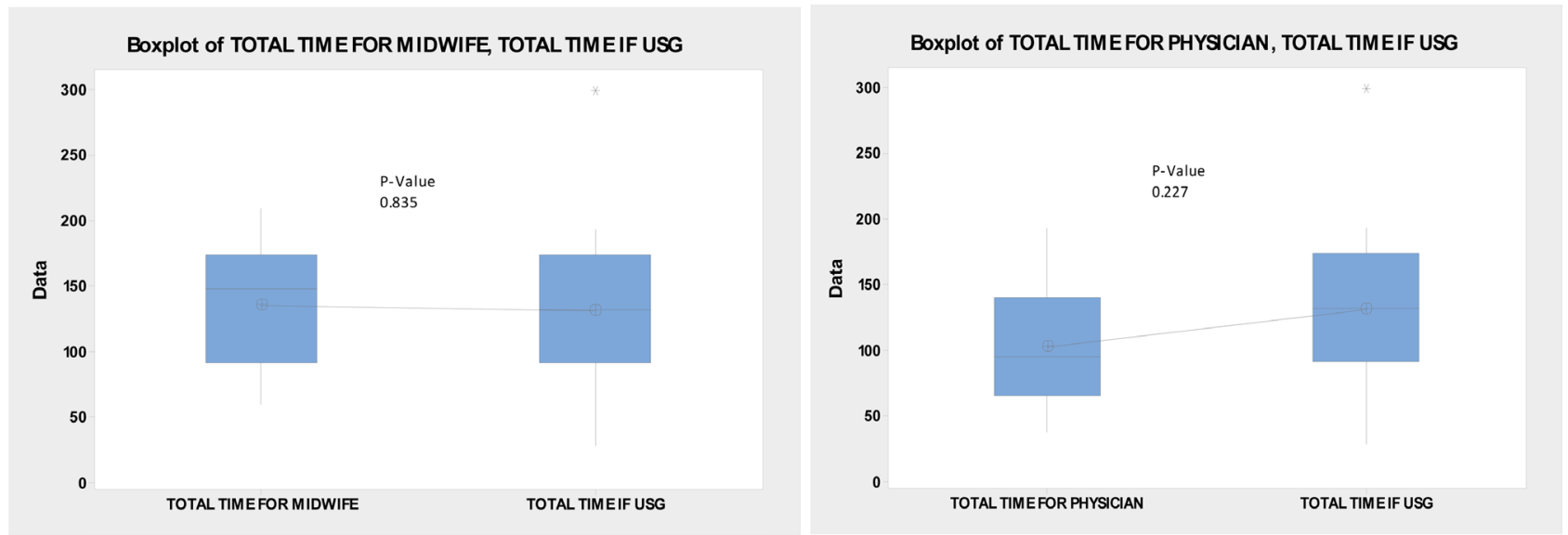

Figure 4. Total time for providers: midwives and physicians versus total time for ultrasound and/or fetal testing.
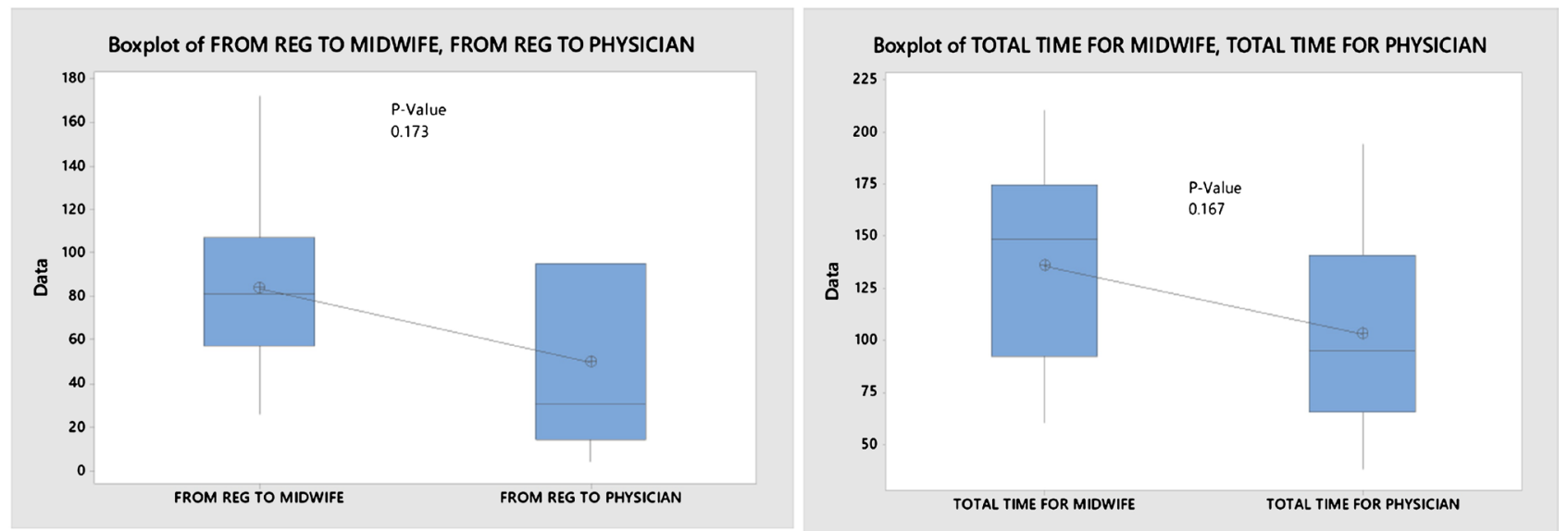

Figure 5. Total time for registration to midwife versus physician and total time in clinic for midwife versus physician. 
us that they spend the same time with patients.

We examined both the time from registration to provider and for total time in clinic and compared midwives and doctors. The difference was not significant.

\subsection{Did Time to Triage and Total Time in Clinic Differ by Arrival Time?}

We plotted the total time in clinic and the triage (vital signs) to provider times throughout the day and examined if weekdays differed. Figure 6 shows these calculations. It suggests that late morning and early afternoon peaked consistently. We examined the clinic scheduling template and noted that all the patients in the morning were double booked in 15 minutes slots and that scheduling began at $8 \mathrm{AM}$ but ended at $3 \mathrm{PM}$. Though there were different clinical activities each day of the week, the schedule was the same. Clinic always seemed to run beyond 5 PM. Though there were different activities each weekday; that did not impact the total time or time to triage.

Other than a spike in the morning at around 9:30 for both total in clinic and for time to provider, there was really nothing else remarkable. The data did not seem to differ much by time of the day. The day started at $8 \mathrm{AM}$ even though providers didn't come until 8:30, 9:30 or 10:00 AM. The day ended on the schedule far earlier than it ended for the patients, ultrasound technicians, and providers. They were all there until after $5 \mathrm{PM}$.

\subsection{What Was the Arrival Rate of the Patients to Clinic?}

As part of the analysis of flow, we calculated the arrival rate of patients to each station and present this in Table 6. We were surprised to learn how few patients arrived at each station.

The arrival rates seemed low when comparing to other outpatient settings, like the emergency room.

\subsection{Did We Have Enough Employees?}

We wondered if we had enough employees at each station. We calculated the arrival rate at each station in the clinic and used Quecalc to calculate the wait time and the number of patients waiting. For the numbers of employees that we had at each station, there was far less than one patient waiting and no one should have been queuing. We went to the GEMBA and observed how many patients were in line at each station. There were always 3 or 4 patients in line for each station but the providers sometimes had up to twenty charts. We realized that we have several bottlenecks: vital signs, provider, checkout, and nursing.

\subsection{Were the Employees Engaged in the Tasks Pertinent to Flow?}

From our observations, we saw that each employee seemed busy but there will still lots of patients waiting, we back calculated using Quecalc and saw that, for the number of patients waiting, our employees appeared to be giving only $10 \%$ 


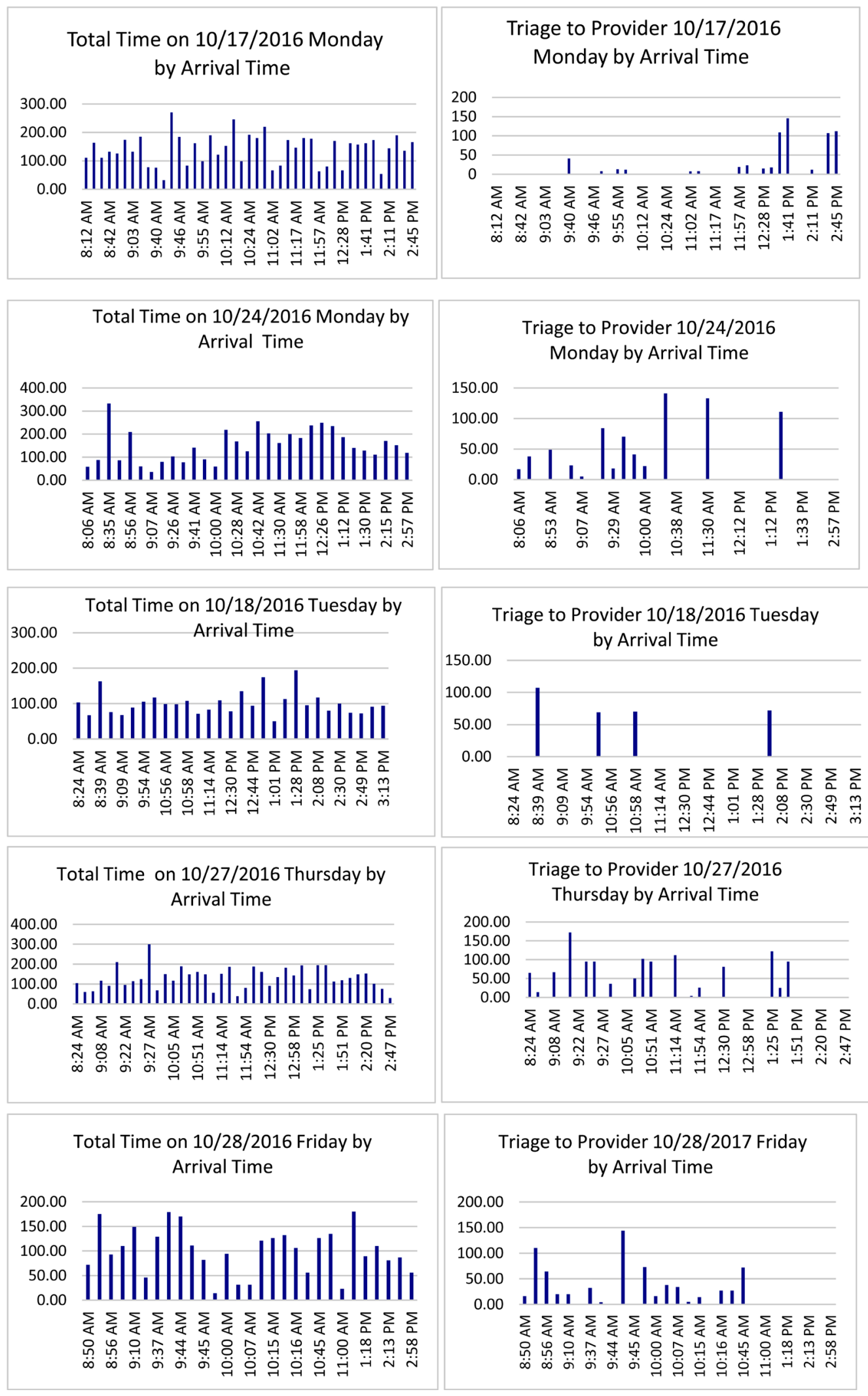

Figure 6. Plots of total time in clinic by arrival time followed by triage to provider by day of the week. In this dataset we have Monday, Tuesday, two separate Thursdays, and Friday. There was no complete dataset for a Wednesday for the pre-intervention time period. 
Table 6. Arrival rate of patients to each station.

\begin{tabular}{lc}
\hline Dates & Oct/Nov 2016 \\
\hline Registration & 4.7 \\
Vital Signs & 4 \\
Providers & 2.1 \\
Checkout & 4.2 \\
Nurses & 1.9 \\
\hline
\end{tabular}

Table 7. Value added processing time given the observed number of patients waiting in each queue.

\begin{tabular}{|c|c|c|c|c|c|}
\hline \multirow[b]{2}{*}{ Station } & \multicolumn{5}{|c|}{ Oct./Nov. 2016} \\
\hline & $\begin{array}{l}\text { Number } \\
\text { of FTE's }\end{array}$ & $\begin{array}{c}\text { Average Time/ } \\
\text { Arrival Time }\end{array}$ & Queuecalc & $\begin{array}{l}\text { Observed } \\
\text { Number }\end{array}$ & $\begin{array}{c}\text { Actual Percent Time of } \\
\text { Employee to Task }\end{array}$ \\
\hline Registration & 3 & $2.6 \mathrm{~min} / 4.7$ & 0.001 & 3 & 0.3 \\
\hline Vital Signs & 4 & $4.5 \mathrm{~min} / 4.0$ & 0.000001 & 4 & 0.4 \\
\hline Providers & 2.5 & $16 \mathrm{~min} / 2.1$ & 0.025 & 3 & 0.7 \\
\hline Check out & 3 & $2.3 \mathrm{~min} / 4.2$ & 0.001 & 3 & 0.3 \\
\hline Nurse & 2 & $8.2 \mathrm{~min} / 2.0$ & 0.013 & 1 & 0.5 \\
\hline
\end{tabular}

of their activity to the bottleneck. We observed them again and found that $90 \%$ of the time they were doing "other work" than checking the patients in and getting them out to see providers. Table 7 shows that less than one patient arriving per hour was predicted by QueueCalc given the number of employees and the time spent. Further, the retrospective calculation showed that our staff were busy but not on the tasks related to flow. The staff was only $30 \%-70 \%$ engaged in value added activities.

From this table we see that we have 4.7 arrivals for 2 hours of bed service. The bed demand is therefore 9.4 /hour.

\subsection{Did We Have Enough Rooms?}

We have 10 rooms: 5 for providers, 1 for fetal testing, 3 for sonography, and 1 for a physician office. Using 9 rooms for patient care. Since we have 9.4 patients/hour and 9 room we are at $104 \%$ capacity. It would be a good idea to liberate the physician office in the clinic.

\subsection{Summary of What We Knew Pre-Kaizen}

It took two hours (124 minutes) to get through clinic. Only 34 minutes were value added time. The remaining 90 minutes were MUDA or waste. We also knew that this did not vary by day of the week nor substantially by time of day. From observing those waiting, we use QueueCallc to figure out what FTE could account for that little productivity and we noted that our employees were 
spending $80-90 \%$ of their time on tasks other than those that move the patients through clinic. We organized the Kaizen event for after my return in January.

\subsection{Kaizen Event}

In preparation for the event, the team began meeting weekly. All the members of the team went to the GEMBA and shared their observations at a weekly meeting.

We established monthly clinic staff meetings and we also had special meetings when problems arose. The clinic staff was encouraged to share their observations, ideas, and suggestions.

We prepared the clinic staff, all providers, and all administration for the event. We shared the data we collected on a Wednesday department meeting that everyone attended. We gave a short but effective lecture on quality improvement and LEAN as a philosophy. It went well. We then went about the task of standardizing the work. We decided to keep collecting data but that we would pick two weeks in March and April to remeasure our variables.

\subsection{Standardizing the Work}

ARRIVAL TIME AND TAKT TIME: We reviewed the template and calculated our NO SHOW rate. The NO SHOW rate had been and continued to be about $15 \%$. The clerks around the institution filled the daily template with 60 patients booked into slots that lasted every 15 minutes from $8 \mathrm{AM}$ to $3 \mathrm{PM}$. The clinic ran from $8 \mathrm{AM}$ to 4 or $5 \mathrm{PM}$ (use 8.5 hours). The TAKT time was 8.5 hours $\times 60$ minutes/35 patients or 14.6 minutes.

Anticipating that the NO SHOW rate would remain about $15 \%$, we hoped to increase our patients seen by $\sim 30 \%$ and go from an average of 35 to 45 . If you use the scheduled arrival time our new arrival rate would allow us to see $45 \mathrm{pa}$ tients/ 8 hours or 5.6 patients per hour. The new TAKT time would be 8.5 hours $\times 60$ minutes $/ 45$ patients or 11.3 minutes.

We learned that we were not using the whole template as patients were not scheduled after $3 \mathrm{PM}$. Also, the providers were $1-1.5$ hours late every day. As changing the template needed institutional approval, we decided met with $\mathrm{C}$-suite about the importance of changing the template. Other clinics had similar templates and we hoped our example could influence other ambulatory sites in the institution. We met with the providers and explained how their behavior affected the entire day for the patients.

\subsection{Work Sequence and Cycle Times}

UPDATE VALUE STREAM MAP: We constructed a more detailed value stream map and quantified the changeover times and verified again how much time was spent at each station. We measure changeover times and noted that not all patients see the nurse. Figure 7 showed the updated Value Stream Map with value added and non-value added activities. As stated earlier, the total time in clinic was 124 minutes but only 34 of those minutes were value added. 


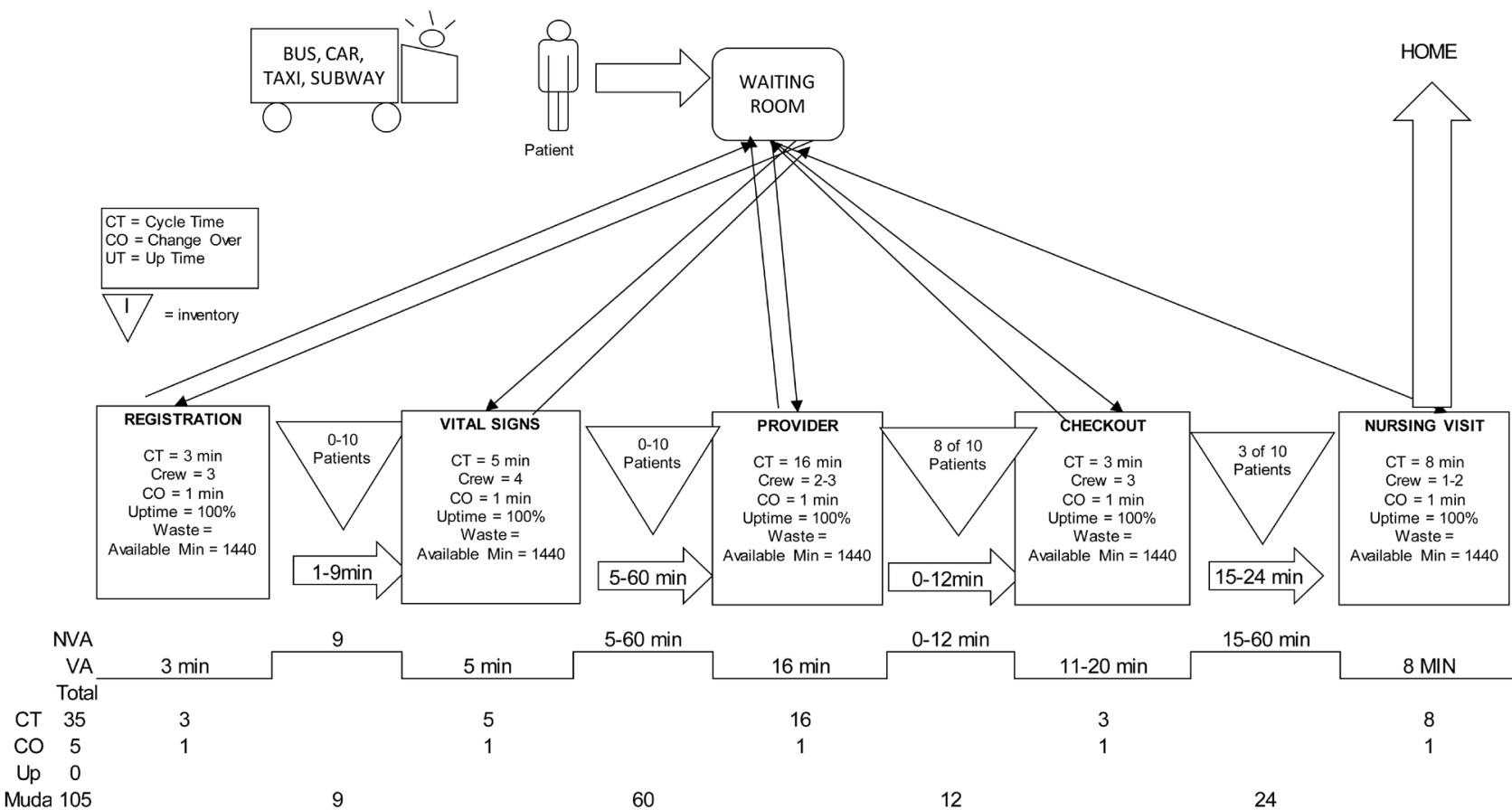

Figure 7. Updated value stream map with flow and changeover times.

\subsection{Spaghetti Diagrams to Examine Flow}

We observed that the registration and checkout staff never moved and that the nurses moved very little. We realized that those who did move were the patients, the medical assistants, and the providers. We constructed spaghetti diagrams for patients, medical assistants, and providers over many days. One day's worth of diagrams is featured. Figure 8 shows the movement of patients, medical assistants, and providers. Providers were an important part of the flow and they were wasting time retrieving patients.

The Spaghetti Diagrams confirmed that there was wasted effort on the part of the patients and providers. We changed the flow using the medical assistants to bring the patient to the provider rather than the provider calling the patient. We also assigned two rooms per providers. They put the next patient waiting for the provider into the provider's free room. This had the effect that waiting was decreased by the patient.

The medical assistants kept track of the number of charts in the basket on each door. When the number of charts was at three, the patient was asked if they minded see another provider. They were informed of the wait if they saw the scheduled provider. Since the patients were empowered to make the decision, they were in control and were happier.

\subsection{Standardizing Each Process}

We worked with each employee to define the steps that really mattered to get the patient through the clinic. Since we knew that only a small effort on their part was committed to this flow, we made the flow the priority and suggested that 


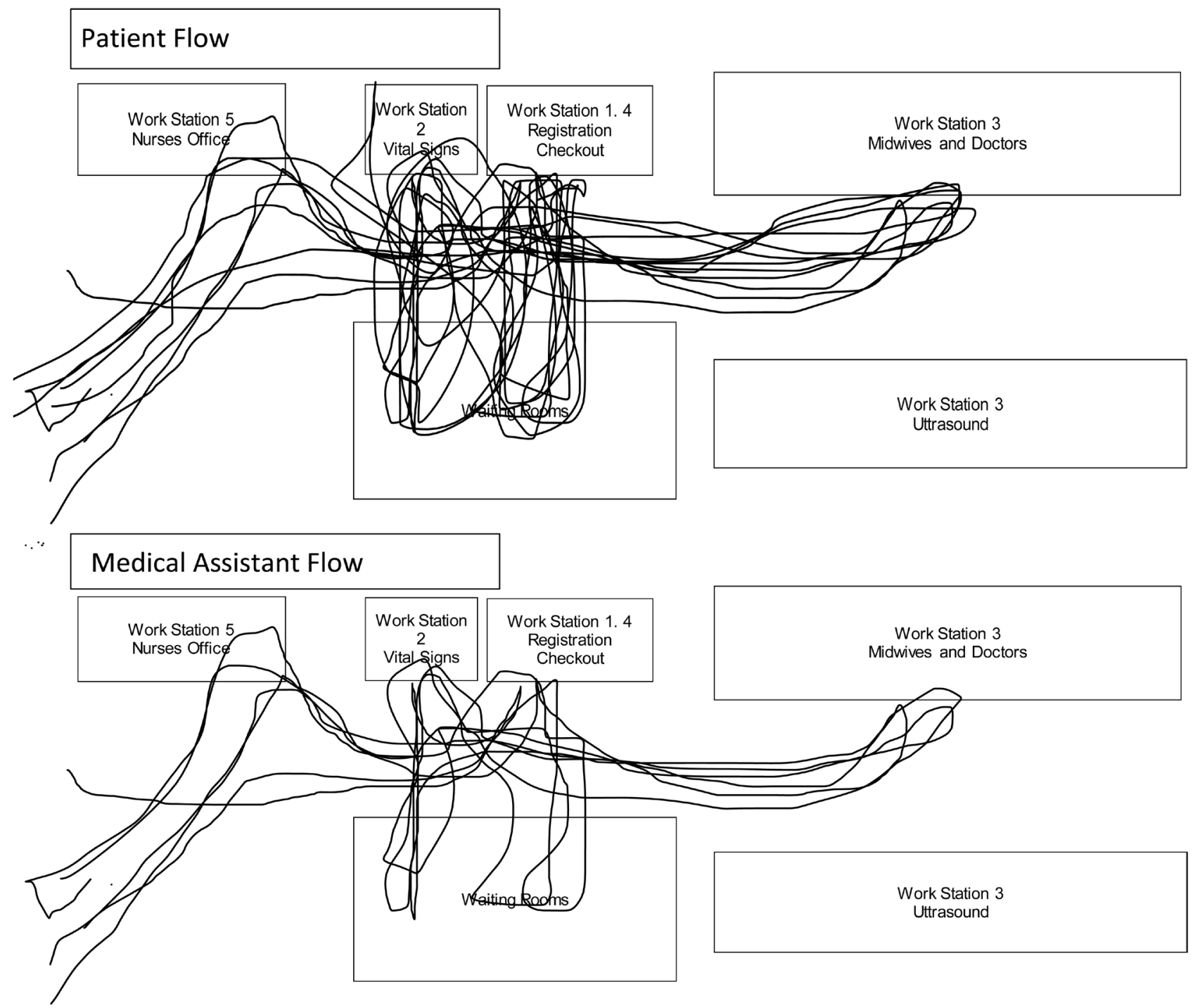

\section{Provider Flow}
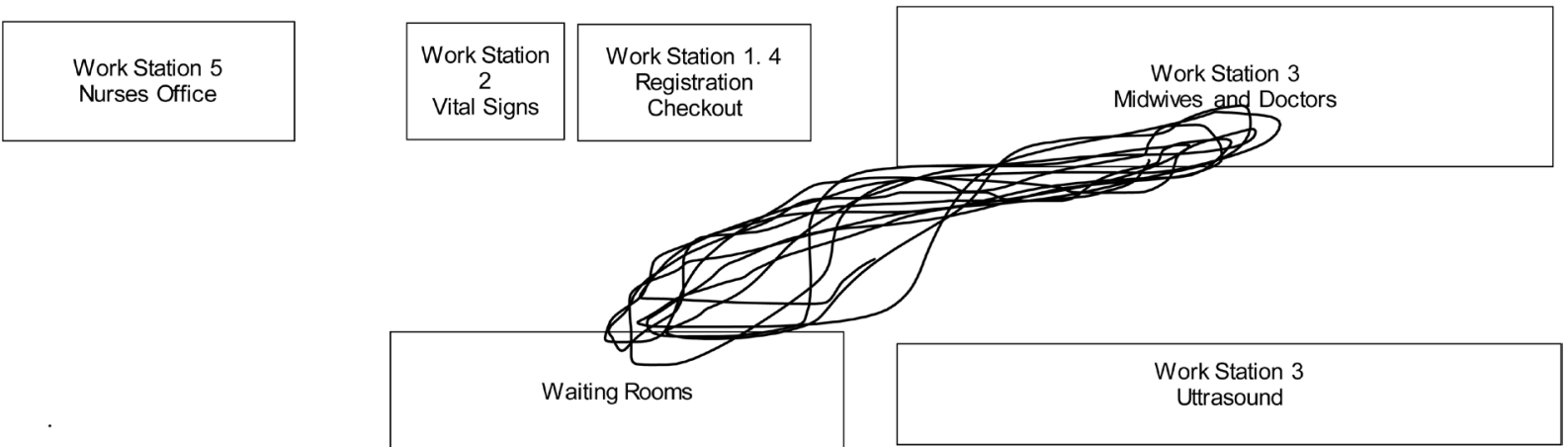

Figure 8. Spaghetti diagrams for patients, medical assistants, and providers.

this would be part of our employee evaluation.

We found that they were all engaged in about 20 other processes during a given day. Some of the processes were quite disruptive. The clerks, for example, 
answered the phones and the inquiries were sometimes health related, schedule related, or general questions. The medical assistants did the stocking of the inventory. This task took them to the sub-sub-basement and took several hours to gather all the supplies that were needed. The providers were often searching for a room with a working computer or they had questions about EPIC and its use in clinic and how that differed from its use in the labor room and emergency rooms. We asked them to engage in these other activities later in the day. We could not remove the phone duty so we left that to be solved at a later time.

\subsection{The Five S'S Sort, Simplify, Sweep, Standardize, and Sustain}

We scheduled a Saturday cleaning event and invited all the staff. At this event, the windows were cleaned, the floors were cleaned, and the equipment in each room was re-organized. The stock room was organized into bins so that the soonest to expire was in the front of the box. The expiration dates were all reviewed and expired clinic materials were discarded. For the rooms in which we carried out procedures, the equipment necessary was stocked. We hung new curtains on the windows and new patient curtains. We reupholstered the exam beds with vinyl and painted the bases so that they were all the same color. We covered all the chairs in the waiting rooms and patient rooms with bright material. We bought some plants. All this greatly cheered the staff and was appreciated by the patients. We put the medical assistants in charge of maintaining the inventory and the room stock.

\subsection{Cause and Effect}

We subjected various parts of our bottlenecks to two LEAN concepts: the five Why's and to the Ishikawa fish diagram. We brainstormed reasons that time was wasted and used our 5 Why's analysis to construct an Ishikawa Diagram. We examined the amount of equipment in the clinic. There was only one vital signs machine and only one scale. There were computers in each clinic room but usually 2 out of 10 didn't work. We noted the clerks doing non-essential tasks while the patients waited to either check in or check out. We noted the medical assistants stocking the clinic during the day when the patients were there. We reiterated how important it was for the providers to be on time.

We engaged the employees in all these activities. We noted that we had visual clues for how the charts built up on the provider clinic room doors but NOT on the fetal testing rooms, nor on the registration/check out area, nor on the medical assistant and nursing areas. We tried to standardize the work as best we could, depending on the employees to help us streamline the processes. Figure 9 shows the Ishikawa diagram.

\subsection{What Was Actually Happening in Clinic Post Kaizen?}

We gathered data for a second intensive period about six months later than the first data but about 10 - 12 weeks after the Kaizen event. First, we examined how many patients were going through each station. We show the new data is Table 8 . 


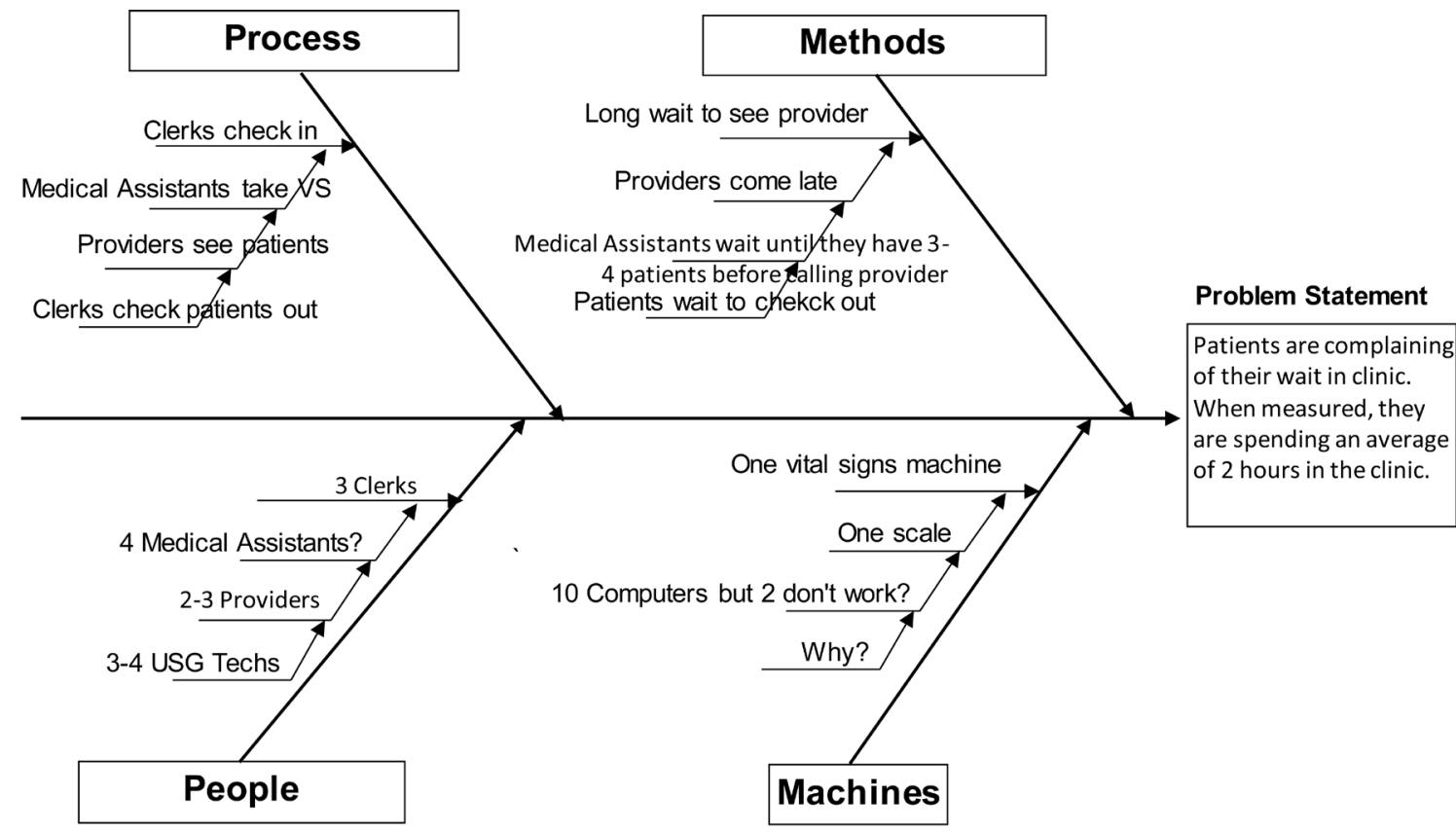

Ishikawa Fishbone Diagram Cause and Effect Diagram

Figure 9. Ishikawa diagram for cause and effect.

Table 8. Average number of patients going through each station for both time periods pre-and post-intervention.

\begin{tabular}{lcc}
\hline DATES & OCT/NOV 2016 & FEB/MAR 2017 \\
\hline Number of Patients who visit Registration & $98 \%$ & $100 \%$ \\
Number of Patients who get Vital Signs & $83 \%$ & $95 \%$ \\
Number of Provider Visits/Total visits & $44 \%$ & $52 \%$ \\
Number of Ultrasound/Biophysical Profile visits & $56 \%$ & $48 \%$ \\
Number of Patients who Checkout & $89 \%$ & $92 \%$ \\
Number of Patients who see Nursing & $40 \%$ & $33 \%$ \\
\hline
\end{tabular}

More patients were visiting each station except the nursing visit. Next, we looked at the minutes in each station.

\subsection{How Long Was Everything Taking Post Kaizen?}

In the post-intervention time period we were seeing an average of 10 patients more (an increase of 28\%). We also had no patient that Left without Being Seen. Those two items were signs of LEAN success (Table 9).

The average minutes at each station were not different but the standard deviations were smaller. We ran $\mathrm{T}$ tests on the means and $\mathrm{F}$ tests on the variances. The average time to triage increased by six minutes and the total time in clinic increased by two minutes. Neither of those changes were statistically significant increases. Figure 10 shows and analysis of each activity demonstrating no statistically significant changes post Kaizen but much less variability in the measurement. 
Table 9. Average number of time and the standard deviation for patients going through each station for both time periods pre-and post-intervention.

\begin{tabular}{lcc}
\hline DATES & OCT/NOV 2016 & FEB/MAR 2017 \\
\hline Average number patients seen /clinic day & 35 & 45 \\
Average Left without being seen & 1 & 0 \\
Average Time Registration (SD) & $2.6 \mathrm{~min}(1.3)$ & $1.8 \mathrm{~min}(0.11)$ \\
Average Time Vital Signs (SD) & $4.5 \mathrm{~min}(1.3)$ & $5.4 \mathrm{~min}(0.77)$ \\
Average Time with Providers (SD) & $16 \mathrm{~min}(4.8)$ & $2.1 \mathrm{~min}(0.43)$ \\
Average Time for Check out (SD) & $2.3 \mathrm{~min}(0.65)$ & $9.6 \mathrm{~min}(1.6)$ \\
Average Time in Nursing (SD) & $8.2 \mathrm{~min}(1.2)$ & $64 \mathrm{~min}(44)$ \\
Average Total Time from Triage to Providers (SD) & $58 \mathrm{~min}(16)$ & $126 \mathrm{~min}(13)$ \\
Average Total Time in Clinic (SD) & $124 \mathrm{~min}(23)$ & \\
\hline
\end{tabular}

Clearly, even after our intervention, none of the data suggested a reduction in time at each station. The decreased variation can be seen in the boxplot but the numerical differences in variances were not statistically significant. Despite the lack of statistical significance, the mood in the clinic had changed. The providers were more engaged. The medical assistants felt empowered. The clerks were engaged and more cheerful. We had no patient complaints and fewer staff complaints. The registration to provider interval was analysis pre- and post-Kaizen and we show in Figure 11 that the changes were not statistically significant.

Unfortunately, the time from registration to provider actually went up, as previously noted, after the intervention and was also more variable. This result however was not statistically significant. Figure 12 shows the total time in clinic pre- and post-Kaizen; again the findings are not significant but in this case the variability is decreased.

Fortunately, the total time in clinic stayed about the same, but diminished in variability.

\subsection{Were the Patients Arriving on Time Post Kaizen?}

When we studied the on time, early arrival and late arrival, we were surprised. Post Kaizen, roughly $5 \%$ of patient arrived on time; but now $60 \%$ arrived early, and only 35\% arrived late. Those that arrived early, arrived an average of $36 \mathrm{mi}-$ nutes early and those that arrived late arrived an average of 32 minutes late. We realized for a second time that the problem was not the patients. We took this as a good sign. The patients improved.

\subsection{Did the Time to Triage and the Total Differ by Time of Arrival or Day of the Week Post Kaizen?}

Again we wondered if the time of day or the day itself made a difference in flow. Here again we plot in Figure 13, the flow for total time and triage to provider time and show very similar results to our pre-Kaizen data. We believe the overloaded 

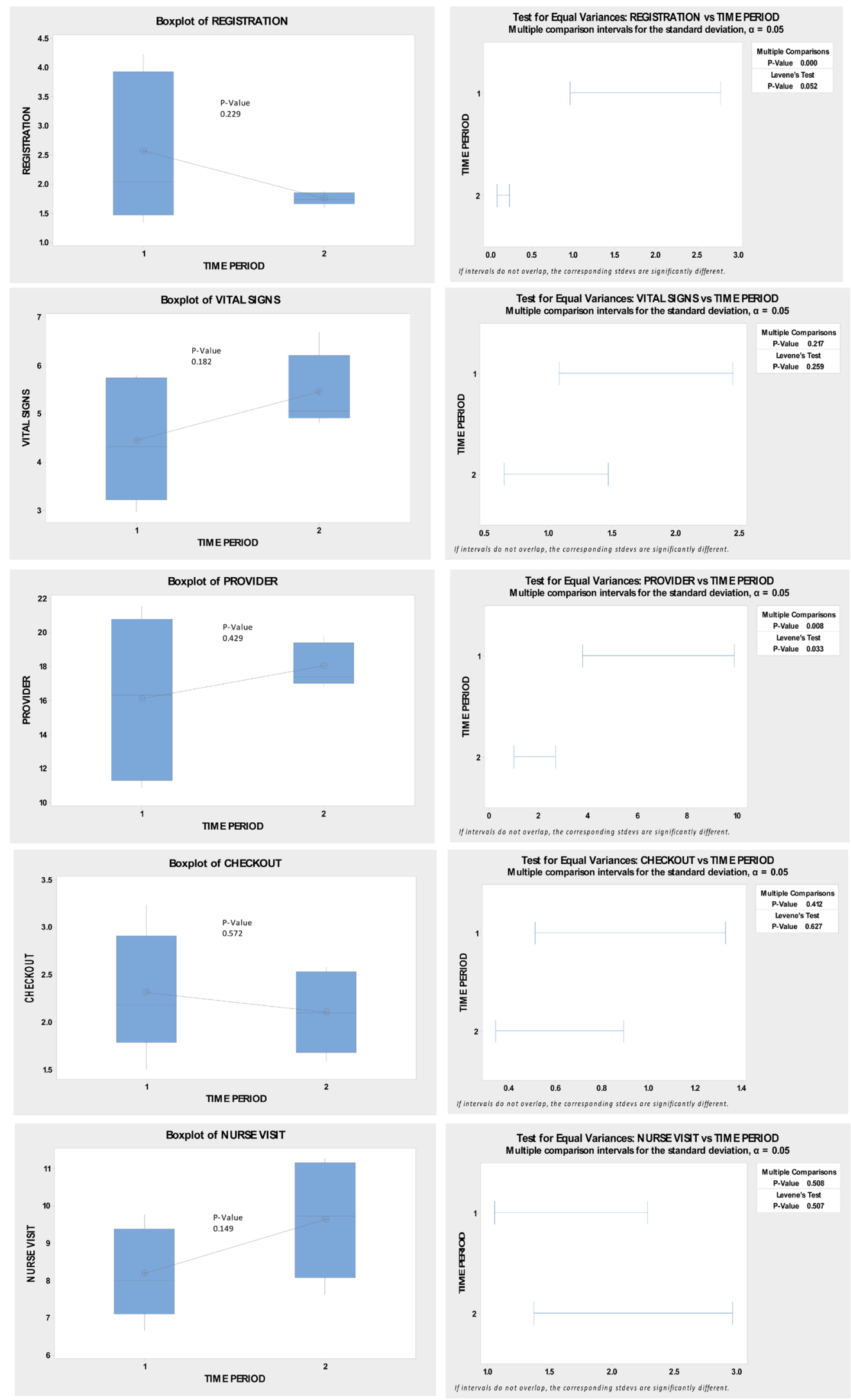

Figure 10. Show boxplots of mean values and their $\mathrm{p}$ values and then Levene's test of variances for the time spent in registration, vital signs, providers, checkout, and the nursing visit. 

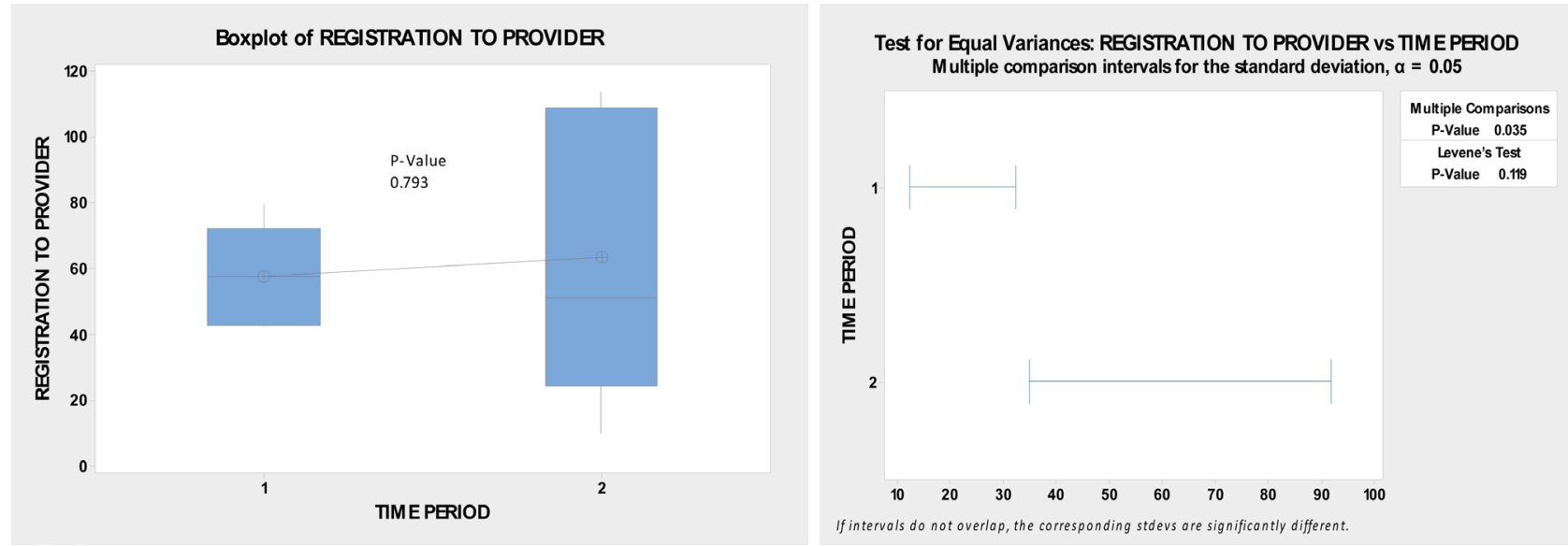

Figure 11. Shows boxplots of means and their $\mathrm{p}$ values and Levene's test of variances for registration to provider time for both times periods.
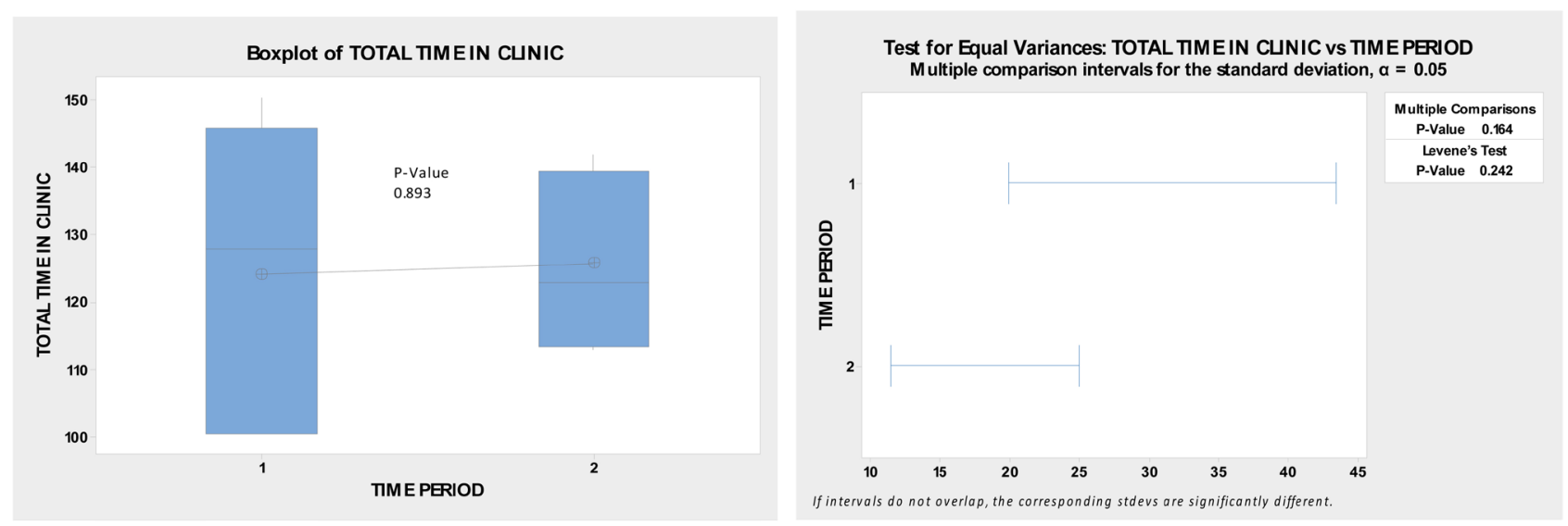

Figure 12. Showing boxplots of means and their $\mathrm{p}$ value and Levene's test of variances for total times in clinic for both times periods.

template accounts for the two spikes.

There seemed to be more waiting at 10 am and $1 \mathrm{pm}$. After careful study, we attributed this to the template which scheduled all patients between 8 am and 3 pm. Again, there appeared no significant differences by day or by time or arrival.

\subsection{Had the Arrival Times Changed?}

New arrival times were calculated, takt times, and service rates were calculated for pre- and post-intervention time periods. Table 10 shows that the post-Kaizen data is improved.

The arrival rates improved; the TAKT times decreased, and most of the service rates improved.

\subsection{Did We Have Enough Employees and Were We Counting Them Correctly?}

Why observed again on the GEMBA and found now only 2 - 3 patients waiting at registration and at vital signs compared to $3-4$ in the past. We felt this cumulative effect was surely due to the flow of patients coming in and getting stuck 


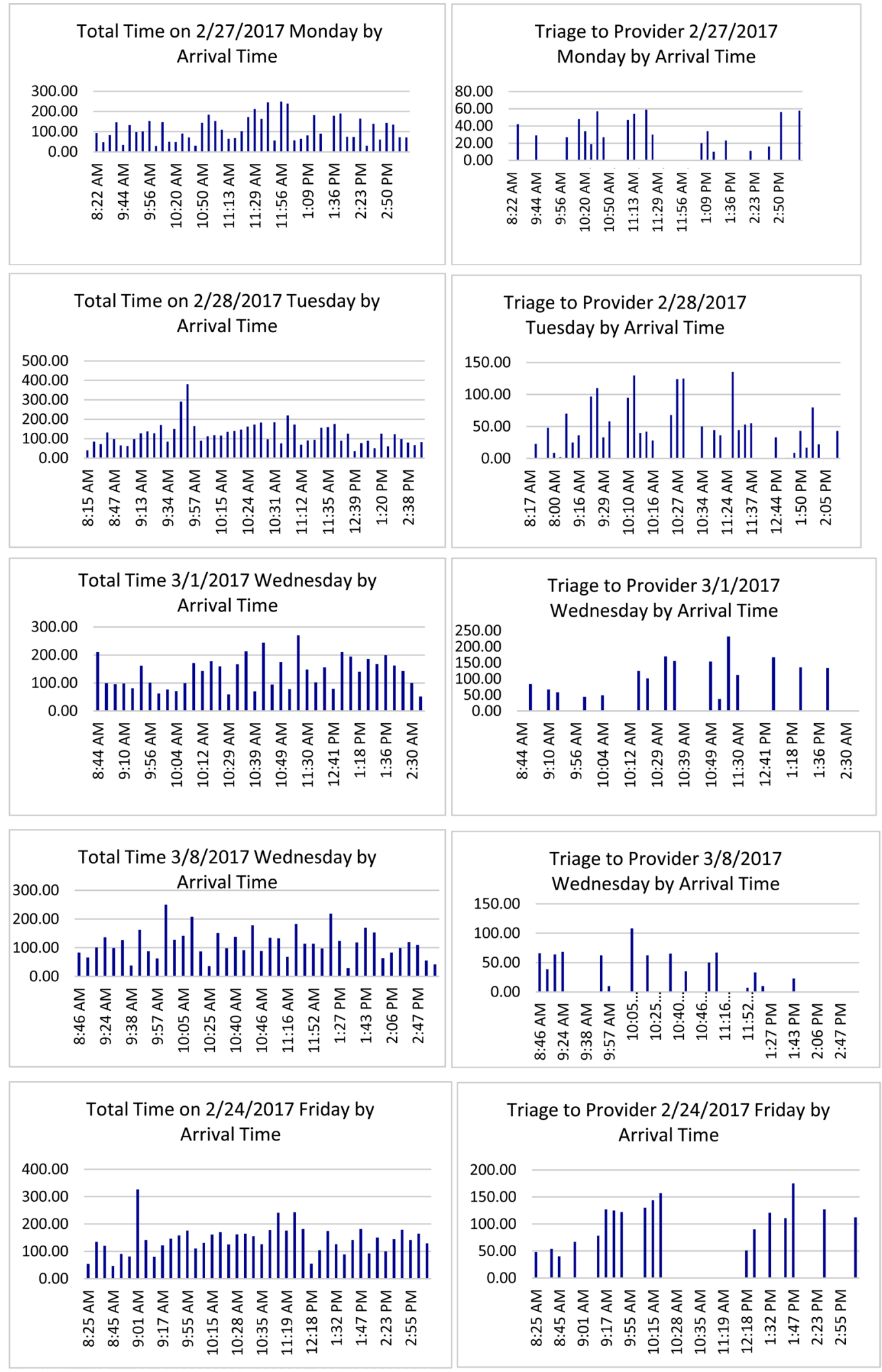

Figure 13. Plots of total time in clinic by arrival time followed by triage to provider by day of the week. In this dataset we have Monday, Tuesday, two separate Wednesdays, and Friday. There was no complete dataset for a Thursday for the post-intervention time period. 
Table 10. Arrival Rates, TAKT times, and Service Rates for both time periods.

\begin{tabular}{lcccccccc}
\hline & \multicolumn{3}{c}{ October/November 2016 Time Period } & \multicolumn{5}{c}{ March/April 2017 Time Period } \\
\cline { 2 - 9 } & $\begin{array}{c}\text { Hourly } \\
\text { Arrival Rate }\end{array}$ & $\begin{array}{c}\text { Hourly } \\
\text { TAKT time }\end{array}$ & $\begin{array}{c}\text { Time to perform } \\
\text { activity in minutes }\end{array}$ & $\begin{array}{c}\text { Hourly } \\
\text { Service Rate }\end{array}$ & $\begin{array}{c}\text { Hourly } \\
\text { Arrival Rate }\end{array}$ & $\begin{array}{c}\text { Hourly } \\
\text { TAKT time }\end{array}$ & $\begin{array}{c}\text { Time to perform } \\
\text { activity in minutes }\end{array}$ & $\begin{array}{c}\text { Hourly } \\
\text { Service Rate }\end{array}$ \\
\hline Registration & 4.7 & 12.8 & 2.6 & 23 & 6 & 10 & 1.8 & 33.3 \\
Vital Signs & 4 & 15 & 4.5 & 13.3 & 5.7 & 10.5 & 5.4 & 11.1 \\
Provider & 2.1 & 28.6 & 16 & 3.75 & 3.1 & 19.4 & 18 & 3.33 \\
Checkout & 4.2 & 14.2 & 2.3 & 26 & 5.5 & 10.9 & 2.1 & 28.5 \\
Nurse & 1.9 & 31.6 & 8.2 & 7.3 & 2 & 30 & 9.6 & 6.3 \\
\hline
\end{tabular}

Table 11. The new analysis of Value Added Processing Time showing available personnel, waiting time calculated using Poisson modelling, the actual observed number of patients in the queue, and the adjustment of time on task based on the number of observed patients in the queue for the post-intervention period.

\begin{tabular}{|c|c|c|c|c|c|}
\hline \multicolumn{6}{|c|}{ VALUE ADDED PROCESSING TIME GIVEN THE OBSERVED NUMBER WAITING IN LINE } \\
\hline \multicolumn{6}{|c|}{ March/April 2017} \\
\hline Station & Number of FTE's & Average Time/Arrival Time & QueueCalc & Observed Number & Actual Percent Time of Employee to Task \\
\hline Registration & 3 & $1.7 \mathrm{~min} / 6.0$ & 0.00001 & 2 & 0.3 \\
\hline Vital Signs & 4 & $5.4 \mathrm{~min} / 5.7$ & 0.002 & 2 & 0.7 \\
\hline Providers & 2.5 & 18.0/3.1 & 0.12 & 2.5 & 1.2 \\
\hline Check out & 3 & $2.1 \mathrm{~min} / 5.5$ & 0.00001 & 2 & 0.3 \\
\hline Nurse & 2 & $9.6 \mathrm{~min} / 1.9$ & 0.008 & 1.5 & 0.4 \\
\hline
\end{tabular}

at each station.

\subsection{Were Our Employees Doing the Tasks That Would Advance Patients through the Clinic?}

Table 11 again analyses the percentage effort of employees on the value-added tasks. The providers increased in productivity from 0.7 to 1.2 by the simple effort of not leaving the room to search for patients and the medical assistants controlling that flow. The work-flow was visual with the baskets on the door of each clinic room. The new rule that help would be called if any basket showed three charts really helped create the pull needed for a lean intervention.

We saw that the queues were lower and that the percent time devoted to employee tasks was higher. While not statistically significant, we saw this as progress good progress.

\subsection{Do We Have Enough Rooms?}

The providers feel most productive when they each can use two rooms with working computers. Converting the physician office would allow two rooms each for our three providers. We set about trying to do that. That was a more complicated task because office space elsewhere was limited and it seemed prudent to have one physician there most of the time. 


\section{Conclusions}

WHAT WE KNEW AFTER THE KAIZEN EVENT: It still took two hours (126 minutes) to get through clinic. We were seeing $28 \%$ more patients (very close to our goal of $30 \%$ ) and we had no patients Leave without Being Seen. The time at each station was unchanged but the variability was decreased. At the time of the second observation, 2 - 3 patients were waiting not 3 - 4. Queuecalc indicated a better percent effort by employees and this increased further when we corrected for leave opportunities. Their effort improved from 10\%-70\% to $30 \%-120 \%$. The lowest value remained at registration which suggested that we overload our clerks with task that don't add value from the patient's point of view.

One activity that was easy to spot, was answering the phone. This took up about a $30 \%-50 \%$ of the clerks' time. We hoped that we could change the way the phones were answered to spare the clerks time.

We understood the ill effects of batching the patients and I had a better feel for bottlenecks and how they accumulate. By observation there will still 2 - 3 patients waiting at registration, vital signs, and providers. But $25 \%$ less was much better than pre-Kaizen.

We looked again at the spaghetti diagrams. Could we change space around? We realized that sinks had been placed in certain rooms to accommodate staff that needed hand washing. We decided to keep asking five WHY's.

We looked at the schedule and found that patients were scheduled more heavily in the morning than the afternoon. We again focused on how we had visual clues on the clinic provider room doors. We realized that we didn't need more clinic staff and we also didn't need more rooms. We in fact needed more visual clues and better standardizing of work.

We did ask management for a second scale and vital signs machine. We embarked on a daily process of assessing the computer stations and made sure they were repaired. We made plans to move the physician office. We put up more visual clues at registration, vital signs, checkout and nursing and continued observation of provider queues. We set the rule that three charts at any station mandated an intervention by the medical assistants. We continued to have the medical assistants control the flow by bringing each patient to the provider. The hardest problem was getting the providers there on time. We saw some improvement after the kaizen but more improvement would be needed to really change the clinic culture. By making posters of our process, we showed both patients and staff our engagement and that translated to great improvements in patient, provider and staff attitudes.

\section{Acknowledgements}

We thank the patients who participated in this trial at Brookdale. We thank Dr. Estevan Garcia for hiring Drs. Follen and Fradkin at Brookdale and for inspiring positive change in an otherwise chaotic environment. At New York City Health and Hospital Corporation Kings County Hospital Center, we also thank Sheldon 
McLeod, our CEO; Opal Sinclair-Chung, our CNO; Graham Gulian, our COO, Steve Pulitzer, our CMO, and Anthony Saul, our CFO, for having the vision to support continual change for betterment in our hospital system. We thank the Johns Hopkins Medicine Armstrong Institute for Patient Safety and Quality for their excellent teaching in the Lean Six Sigma Course and the instructors' suggestions for improvement as the study progressed.

\section{Conflicts of Interest}

The authors declare no conflicts of interest regarding the publication of this paper.

\section{References}

[1] Deming, W.E. (1994) The New Economics, for Industry, Government, and Education. MIT Press, Cambridge, MA.

[2] Deming, W.E. (2013) The Essential Deming; Leadership Principles Form the Father of Quality. In: Orsini, J.N., Ed., McGraw-Hill, New York, NY.

[3] Columbia Business School. n.d. The W. Edward Deming Center for Quality, Productivity, and Competitiveness. http://www.8gsb.columbia.edu

[4] Shewhart, W.A. (1986) Statistical Method from the Viewpoint of Quality Control. In: Deming, W.E., Ed., Dover Publications Inc., New York, NY.

[5] St. Andrews. n.d. St. Andrews College UK. http://www-history.mcs.st-andrews.ac.uk/Biographers/Shewhart.html

[6] Katz, J.and Green, E. (1992) Managing Quality: A Guide to Monitoring and Evaluating Nursing Services. Mosby Yearbook, St. Louis, MO.

[7] Katz, J. (1997) Managing Quality: A Guide to System-Wide Performance Management in Health Care. Mosby, St. Louis, MO.

[8] Liker, J.K. (2004) The Toyota Way; The Company That Invented Lean Production. McGraw-Hill, New York, NY.

[9] Liker, J.K. and Meier, D. (2006) The Toyota Way Fieldbook; a Practical Guide for Implementing Toyota's 4Ps (Philosophy, Process, People and Partners, Problem) Solving. McGraw-Hill, New York, NY.

[10] Liker, J.K. and Franz, J.K. (2011) The Toyota Way to Continuous Improvement; Linking Strategy and Operational Excellence to Achieve Superior Performance. McGraw-Hill, New York, NY.

[11] Liker, J.K. and Convis, G.L. (2012) The Toyota Way to Lean Leadership; Achieving and Sustaining Excellence through Leadership Development. McGraw-Hill, New York, NY.

[12] Liker, J.K. and Ross, K. (2017) The Toyota Way to Service Excellence; Lean Transformation in Service Organizations. McGraw-Hill, New York, NY.

[13] University of Michigan. n.d. University of Michigan. https://ioe.engin.umich.edu/people/jeffrey-liker/

[14] Womack, J.P. and Jones, D.T. (2005) Lean Solutions; How Companies and Customers Can Create Value and Wealth Together. Free Press; Simon and Schuster Inc., New York, NY.

[15] Womack, J.P., Jones, D.T. and Roos, D. (2007) The Machine That Changed the World. Free Press; Simon and Schuster Inc., New York, NY.

[16] Womack, J.P. (2013) Gemba Walks. Lean Enterprise Institute, Cambridge, MA. 
[17] Lean Enterprise Institute (n.d.) Lean Enterprise Institute. https://www.lean.org

[18] Rother, M. and Shook, J. (2000) Value-Stream Mapping Workshop: Participant Guide. Lean Enterprise Institute, Cambridge, MA.

[19] Rother, M. and Shook, J. (2009) Learning to See: Value-Stream Mapping to Create Value and Eliminate MUDA. Lean Enterprise Institute, Cambridge, MA.

[20] Shook, J. (2010) Managing to Learn: Using the A3 Management Process to Solve Problems, Gain Agreement, Mentor and Lead. Lean Enterprise Institute, Cambridge, MA.

[21] Rother, M. (2010) Toyota Kata: Managing People for Improvement, Adaptiveness, and Superior Results. McGraw-Hill, New York, NY.

[22] Ohno, T. (1988) Toyota Production System: Beyond Large-Scale Production. CRC Press; Taylor and Francis, Boca Raton, FL.

[23] Harada, T. (2015) Management Lessons from Taiichi Ohno. Translated by Brad Schmidt, McGraw-Hill, New York, NY.

[24] Wakamatsu, Y. (2009) The Toyota Mindset: The Ten Commandments of Taiichi Ohno. Edited by Collin McLoughlin, Translated by Junpei Nakamuro, Enna Products Corp., Bellingham, WA.

[25] Toyota Motor Corp. (1988) Toyota: A History of the First 50 Years. Toyota Motor Corp., Toyota City, Aichi Prefecture.

[26] Shingo, S. (2007) Kaizen and the Art of Creative Thinking. PCS Inc., Vancouver, WA.

[27] Black, J. and Miller, D. (2008) The Toyota Way to Healthcare Excellence: Increase Efficiency and Improve Quality with Lean. Health Administration Press, Chicago, IL.

[28] Black, J. (2016) The Toyota Way to Healthcare Excellence: Increase Efficiency and Improve Quality with Lean. Health Administration Press, Chicago, IL.

[29] Chalice, R. (2010) Improving Healthcare Using Toyota Lean Production Methods: 46 Steps for Improvement. 2. Quality Press, Milwaukee, WI.

[30] Crane, J. and Noon, C. (2011) The Definitive Guide to Emergency Room Operational Improvement. CRC Press, Taylor and Francis Group, Boca Raton, FL. https://doi.org/10.4324/9781439895382

[31] Dean, M.L. (2013) LEAN Healthcare Deployment and Sustainability. McGraw Hill, New York, NY.

[32] Gabow, P.A. and Goodman, P.L. (2015) The Lean Prescription: Powerful Medicine for Our Ailing Healthcare System. CRC Press, Taylor and Francis Group, Boca Raton, FL.

[33] Graban, M. and Swartz, J.E. (2012) Healthcare Kaizen: Engaging Front-Line Staff in Sustainable Continuous Improvements. CRC Press, Taylor and Francis Group, Boca Raton, FL.

[34] Graban, M. (2016) Lean Hospitals, Improving Quality, Patient Safety, and Employee Engagement. CRC Press, Boca Raton, FL.

[35] Grunden, N. (2008) The Pittsburgh Way to Efficient Healthcare. CRC Press, Taylor and Francis Group, Boca Raton, FL.

[36] Hoeft, S. and Pryor, R.W. (2016) The Power of Ideas to Transform Healthcare: Engaging Staff by Building Daily Lean Management Systems. CRC Press, Taylor and Francis Group, Boca Raton, FL.

[37] Inozu, B., Chauncey, D., Kamataris, V. and Mount, C. (2012) Performance Im- 
provement for Healthcare: Leading Change with Lean, Six Sigma, and Constraints Management. McGraw Hill, New York, NY.

[38] Lighter, D.E. (2011) Advanced Performance Improvement in Health Care: Principles and Methods. Jones \& Bartlett Publishers, Sudbury, MA.

[39] Lighter, D.E. (2013) Basics of Health Care Performance Improvement: A Lean Six Sigma Approach. Jones and Bartlett Learning, Burlington, MA.

[40] Miller, L.M. (2012) HealthCare LEAN. Miller Management Press LLC, Annapolis, MD.

[41] Morrow, R. (2012) Utilizing the 3 Ms of Process Improvement in Healthcare: A Roadmap to High Reliability Using LEAN, SIX SIGMA, and Change Leadership. CRC Press, Boca Raton, FL.

[42] Plsek, P. (2014) Accelerating Health Care Transformation with Lean and Innovation: The Virginia Mason Experience. CRC Press, Boca Raton, FL.

[43] Stamatis, D.H. (2011) Essentials for the Improvement of Healthcare Using LEAN and SIX SIGMA. CRC Press, Boca Raton, FL.

[44] Toussaint, J. and Gerard, R.A. (2010) On the Mend: Revolutionizing Healthcare to Save Livers and Transform the Industry. Edited by Lean Enterprise Institute. Lean Enterprise Institute, Cambridge, MA.

[45] Toussaint, J. (2012) Potent Medicine: The Collaborative Cure for Healthcare. ThedaCare Center for Healthcare Value, Appleton, WI.

[46] Toussaint, J. (2015) Management on the Mend: The Healthcare Executive Guide to System Transformation. ThedaCare Center for Healthcare Value, Appleton, WI.

[47] Zidel, T.G. (2006) A Lean Guide to Transforming Healthcare: How to Implement Lean Principles in Hospitals, Medical Offices, Clinics and Other Healthcare Organizations. Quality Press, Milwaukee, WI.

[48] Zidel, T.G. (2017) Rethinking Lean in Healthcare: A Business Novel on How a Hospital Restored Quality Patient Care and Obtained Financial Stability Using Lean. CRC Press; Taylor and Francis Group, Boca Raton, FL. 